\title{
Creating public space through urban analysis
}

\author{
Liliia Talipova $^{1 *}$, Arseniy Lyubomirskiy ${ }^{1}$, Daria Povarenko ${ }^{1}$, and Alexander Scherbakov ${ }^{2}$ \\ ${ }^{1}$ Peter the Great St. Petersburg Polytechnic University, 29 Politechnicheskaya St., St. Petersburg, \\ 195251, Russia \\ ${ }^{2}$ Saint Petersburg State University of Architecture and Civil Engineering, Vtoraya Krasnoarmeiskaya \\ street, 4, Saint Petersburg, 190005, Russia
}

\begin{abstract}
The article researches purpose is to create a project of improvement of the right side of Kushelevskaya road through urban analysis. The transformation of the studied area will can lead to the improvement of the visual environment, creation of public spaces, landscaping of the adjacent territory, creation of visual code and new points of development and growth of the district. The study analyzes the physical and social environment, considers social scenarios. A SWOT analysis of the study area and a development map was carried out.
\end{abstract}

\section{Introduction}

In the conditions of urban space development, special attention should be paid to the environment people live in. By the end of 20171043 houses including 69508 apartments had been put in service in St. Petersburg [1], which is $14 \%$ more then by the end of 2016 . With the introduction of new buildings, the lack of public spaces gets more prominent. This happens due to the fact that the developer is only interested in improving the local area, but not the space adjacent to it. One of such areas where the number of new buildings grows every year, but the quality of public spaces decreases, is the Kushelevskaya road. At the moment 13 new buildings are put in service along the Kushelevskaya and 7 more are waiting in line. Such urbanists and architects as Vyatcheslav Glazychev, Jane Jacobs, Rem Koolhaas, Richard Florida were involved in the study of urban space. In the work "Urban designer", Vitold Rybczynski described urbanists' methods of creating public space [2]. In 2016, the Strelka Institute developed guidelines "16 knots of good streets" and "Streets Improvement», which were accepted and approved in Russia.

The researches purpose is to create a project of improvement of the right side of Kushelevskaya road through urban analysis.

Research problems were:

1) to analyze the physical environment of the studied area;

2) to analyze the social environment of the studied area;

3) to identify strengths, weaknesses, opportunities and threats of the studied area;

4) to propose the project of the territory improvement based on the achieved results.

*Corresponding author: talipova 1v@s,spbstu.ru 


\section{Research of the physical and social environment}

The bounds were determined at the first stage of the research and composed $1 \mathrm{~km}$ in diameter (Figure 1).

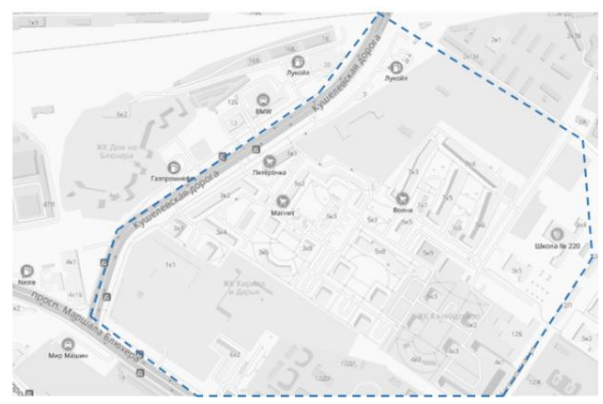

Fig. 1. Research borders

Further physical and social environments of the city space were analyzed. Building and constructions, landscape gardening, small architecture forms, transport, roads, advertising signs and banners are refers to the objects of the physical environment [10-12].

Green spaces were defined in the studying area with the aim of analysis of gardening's percentage ratio. The index was equal to $10 \%$ what means landscape gardening is not enough (Figure 2).

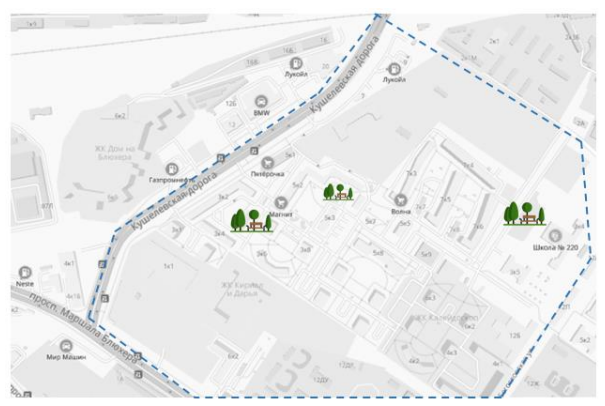

요요 - parks

Fig. 2. Sites of gardening

A bus (№60 - Lesnaya -Prospekt Prosveshcheniya), trolley bus (Lesnaya Akademicheskaya) and commercial traffic routes represent the transport infrastructure. The nearest subway station Lesnaya is located $1,5 \mathrm{~km}$ from the studying area (Figure 3 ). According to normative documents working radius of municipal transport's stops is $500 \mathrm{~m}$. The lack of ground transport's stops at the station Kushelevskaya doroga and organization of surface level pedestrian crossing was found out in the studying area. 


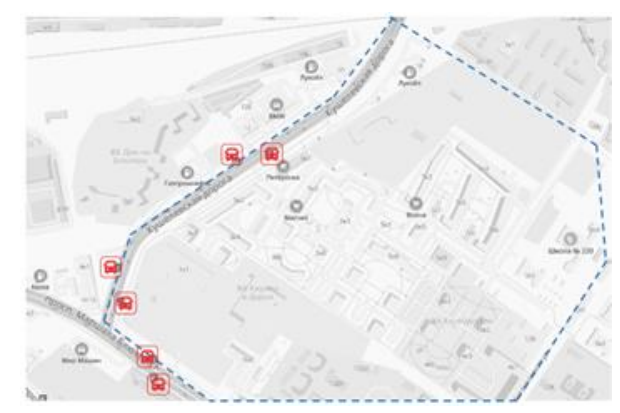

Fig. 3. Transport accessibility

Schools, nursery schools refer to the social infrastructure. There is a polyclinic in a radius of $1 \mathrm{~km}$ from the studying area. Problems in the social infrastructure were not disclosed.

There is an aggressive visual environment in the studying area, which consist in various and inelegant advertising signs, afunctional open grounds. There is an absence of landscaped spaces and many roads leading to the objects of social infrastructure are in critical condition. All of these makes the area look depressive.

Social scenarios of using the area may be two types: obligatory and non- obligatory. Obligatory social scenarios involve jobs, maintenance, transit and non- obligatory social scenarios include meeting points and leisure. Then more non- obligatory social scenarios, the better the environment. During the analysis of social environment, it was cleared up that people of different ages use the area. $4 \%$ of them are younger than 20 years, $58 \%-20-30$ years old, 37\% - 30-55 years old, 15\% are older than 55 years. Popular social scenarios for the studying object are jobs, walk with kids, cycling and transit. Basic social types, which were determined during the analysis, present students, non-manual workers, pensioners, workers and mothers with children. There is no non- obligatory social scenarios in the area now.

\section{Results}

The studied area has a minimum size equal to $35 \mathrm{~m}$, measured from residential house to the adjacent road.

It is planned to organise a parking bay along Kushelevskaya road with ground level car park to provide a safe way out from the territory of residential complexes. Provision of adequate traffic is another purpose of this. Due to the residents of the district leave their vehicles in the rightmost traffic lane in rush hours there is a large traffic jam going from Marshal Blyuher avenue to Nepokorennyh avenue which is estimated at 8.5 out of 10 according to Yandex Maps because only 2 of 3 traffic lanes stay free. This site will be surrounded by greenery with several ways out to the pedestrian area and a metal fence from the Kushelevskaya road side. Parking spaces will be angled at 45 degrees to the traffic in order to increase their number in a limited area. The initial number of parking spaces between the first way out from the district and the future transit shelter was 32 , and now is $47(50 \%$ more), 6 of which are meant for disabled people.

The organization of cycle paths including two lanes of standard sizes is provided.

The footpath runs along the house, has branches for approaching to commercial spaces located on the ground floor of the building. These branches are separated by small areas of greenery. It is planned to place a dog run, surrounded by greenery, which will include both space for walking the pets and a recreation area for their owners. 
The design of green areas is planned with fences and benches located on them. On the border of these zones trash bins and benches for disabled people are planned to be located at least every $100-150 \mathrm{~m}$.

There is also allocated space for a street fair with the placement of objects for trade, where local residents or other people will be able to present their goods and services.

In the same part of the territory, a transit shelter and a controlled pedestrian crossing are planned to be arranged. Since one side of the studied area is adjacent to the road with active traffic, species with noise insulation properties and which are able to purify the air, absorbing harmful substances and precipitating suspended dust particles on the surface of their leaves should be used as greenery. Such plants include the following: Norway maple, small-leafed and large-leafed Linden, horse chestnut, common and black ash, Siberian and European larch, common and Hungarian lilac, etc.

The transformation of public space is shown in figure 4.
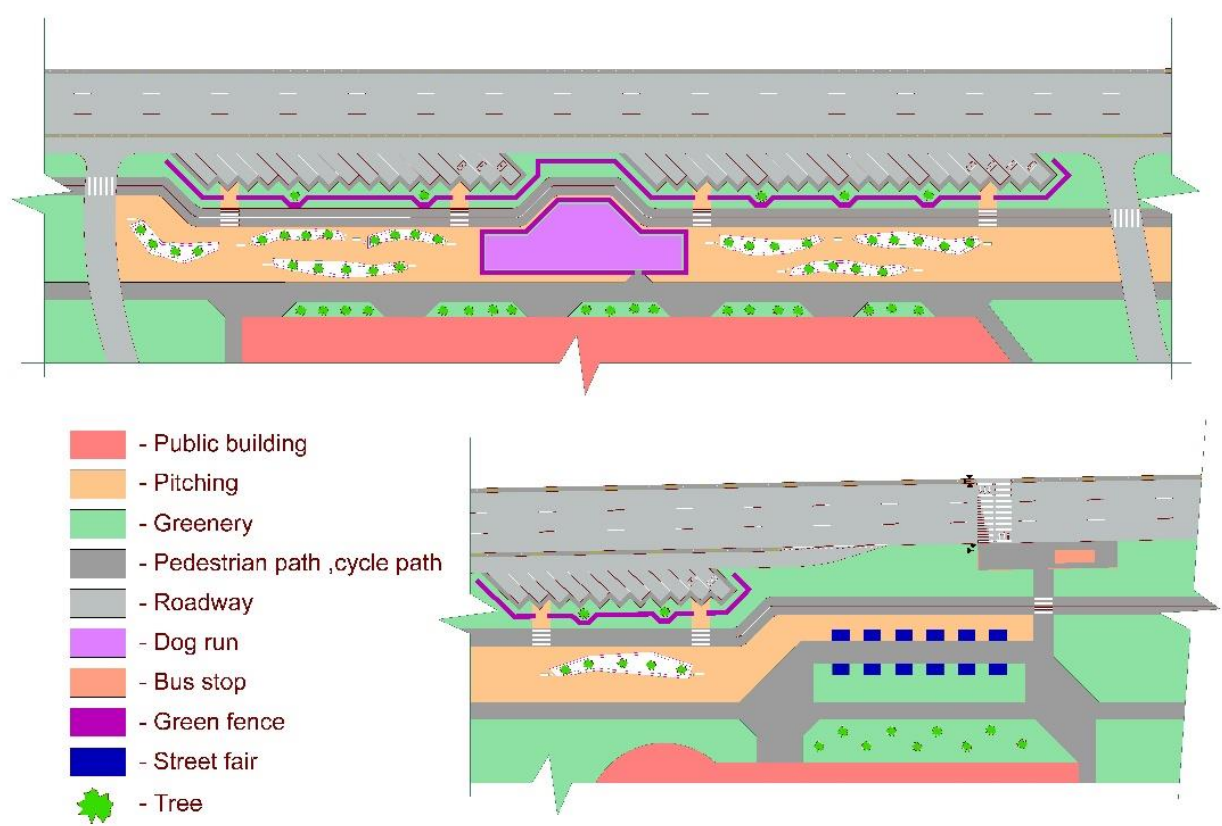

Fig. 4. Transformation of public space

\section{Discussion}

Creation of the parking bay with adjacent parking and installation of the metal fence on its border with the rest of the road may lead to reducing the likelihood of accidents and have a positive impact on the transport situation in the area. Cycle paths which allow people to use more eco-friendly transport instead of cars can also affect this aspect. Creation of a dog run and a street fair zone will cause a change of social scenario from transit to unnecessary ones such as meeting point or recreation. The first one is especially relevant due to the fact that there are quite a lot of people living in this area with dogs as pets.

Arrangement of the transit shelter is necessary because the distance between two existing ones is more than $1.5 \mathrm{~km}$ and according to the analysis this area is used by residents of the district as an improvised shuttle bus stop. 
Construction of controlled pedestrian crossing will help to connect the sides of the road and mitigate the dangerous road situation which was also discovered by the analysis.

Selected types of greenery will help to reduce the negative impact of transport.

\section{Conclusions}

For a visual demonstration of the results of the physical and social environment study, a SWOT analysis was compiled in Table 1.

Table 1. SWOT analysis

\begin{tabular}{|c|c|}
\hline Strengths & Weaknesses \\
\hline $\begin{array}{ll}\text { - } & \text { Location } \\
\text { - } & \text { Developed social infrastructure }\end{array}$ & $\begin{array}{ll}\text { - Insufficient gardening } \\
\text { - Not well-groomed environment }\end{array}$ \\
\hline Opportunities & Threats \\
\hline $\begin{array}{ll}\text { - } & \text { A large number of students } \\
\text { - } & \text { A large number of employees } \\
\text { - } & \text { Inflow of new residents } \\
\text { - } & \text { Interest from developers }\end{array}$ & $\begin{array}{ll}- & \text { Social differentiation } \\
- & \text { insufficient social infrastructure }\end{array}$ \\
\hline
\end{tabular}

The transformation of the studied area will lead to the improvement of the visual environment, creation of public spaces, landscaping of the adjacent territory, creation of visual code and new points of development and growth of the district.

According to urban sociologist Ray Oldenburg, people need three types of places to live fulfilled, connected lives: Their "first place" (home) for private respite; their "second place" (work) for economic engagement; and their "third place," a more amorphous arena used for reaffirming social bonds and community identities [13]. This third place can be a barbershop, neighborhood bar, community center, or even a public square. The desire for these three separate spheres drives how human environments are designed at a bedrock level, but increasing urbanism - as well as geographic and economic mobility-are collapsing these multiple spaces into one. In this article, the result of the study is the creation of a public space as a "third place", which will gather the residents of nearby houses.

\section{References}

2 The volume of housing construction in St. Petersburg https://gazeta.bn.ru/news/2018/01/11/243650.html

3 W. Rybczynski Makeshift Metropolis: Ideas about Cities (2015)

4 M. R. Rahnama, H. Yazdanfar, Management Science Letters, 4(1), 203-206 (2014). doi:10.5267/j.msl.2013.12.009

5 M.C. Dejaco, F. Re Cecconi, S. Maltese, Journal of Building Engineering, 9, 17-28 (2017). doi:10.1016/j.jobe.2016.11.004

6 G. Croatto, U. Turrin, A. Bertolazzi, Journal of Architectural Conservation, 22(3), 189198 (2016). doi: 10.1080/13556207.2017.1279866

7 K. Dyson, J. Matthews, Love P.E.D., Built Environment Project Asset Management, 6(1), 44-57 (2016). doi:10.1108/bepam-01-2015-0002

8 P.A. Jensen, E. Maslesa, Building and Environment, 92, 1-9 (2015). doi:10.1016/j.buildenv.2015.04.008

9 J. Ferreira, M. Duarte Pinheiro, J. De Brito, Journal of Building Engineering, 3, 114126 (2015). doi:10.1016/j.jobe.2015.07.001 
10 D. Rink, et al. 'Governance of Shrinkage - Lessons Learnt from Analysis for Urban Planning and Policy'. Leipzig: Helmholtz Centre for Environmental Research - UFZ, 2012

11 F. Ascione, F. De Rossi, G.P. Vanoli, Energy and Buildings, 43, 1925-1936 (2011). doi:10.1016/j.enbuild.2011.03.040

12 O. Romice, K. Thwaites, S. Porta, M. Greaves, G. Barbour, P. Pasino, Handbook of Environmental Psychology and Quality of Life Research. 241-275 (2017). doi:10.1007/978-3-319-31416-7_14

13 V.L. Castaldo, A.L. Pisello, P. Boarin, A. Petrozzi, F. Cotana, Buildings, 7 (2), 52 (2017). doi:10.3390/buildings7020052

14 Live, Work, Play: WeLive's Live-Work Spaces Reveal a "Third Place": [Electronic resource]: Redshift by Autodesk. 2016. URL: https://www.autodesk.com/redshift/livework-spaces/ 